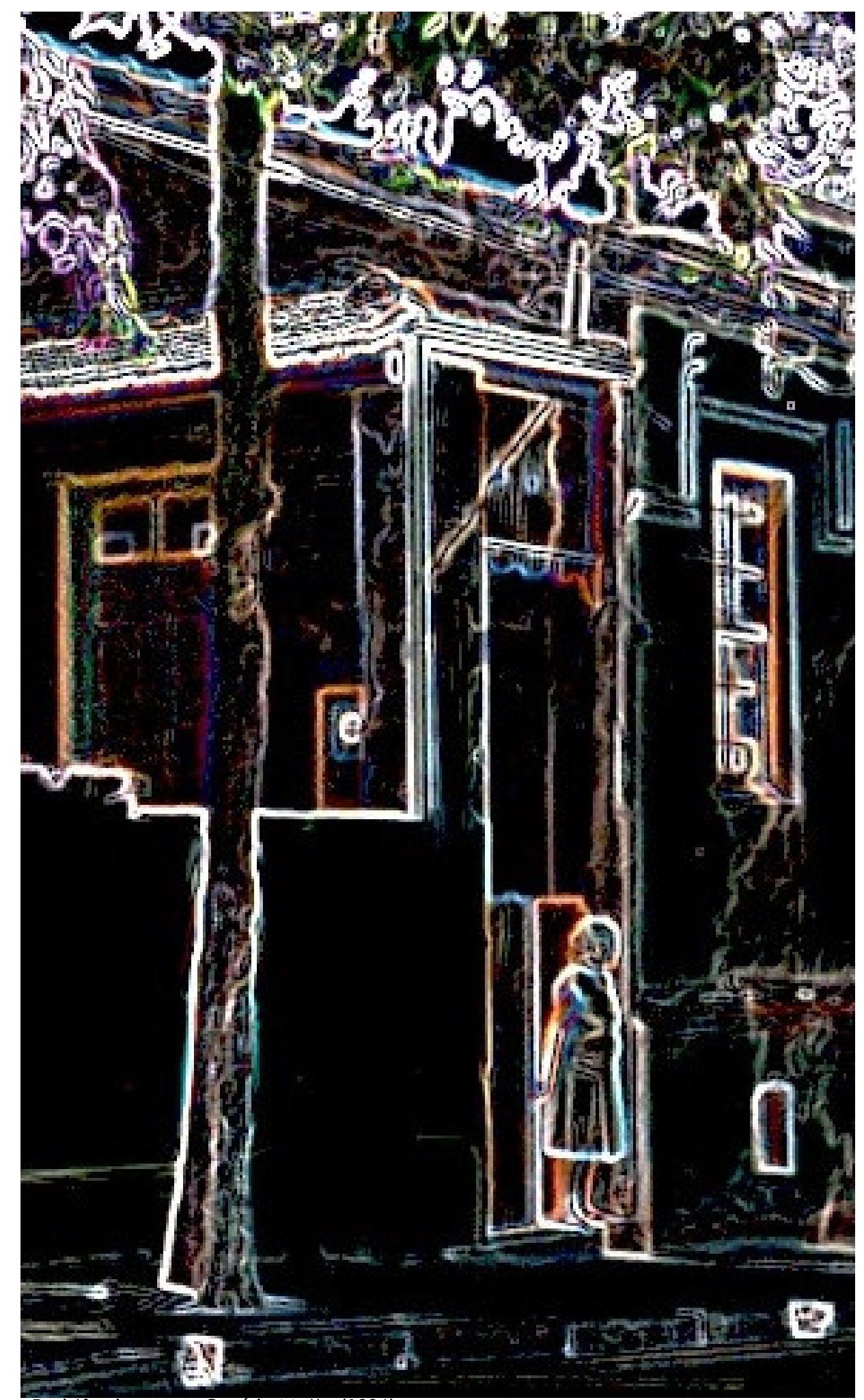

Residência na rua Cesário Motta (1996)

Proteção da Paisagem Ferroviária:

MEMÓRIA E IDENTIDADE do BAIRRO ESTAÇÃo

SÃo Bernardo (ATUAl SANTo ANDRÉ, SP)

Silvia Helena F. Passarelli

São Paulo, 2005. 


\section{Proteção da Paisagem Ferroviária: \\ MEMÓRIA E IDENTIDADE do BAIRRO ESTAÇÃo \\ São Bernardo (Atual SANto André, SP)}

Silvia Helena F. Passarelli

São Paulo, 2005. 


\author{
UNIVERSIDADE DE SÃo PaUlo \\ FACULDADE DE ARQUITETURA E URBANISMO \\ Curso de Pós-Graduação
}

\title{
ProteçÃo da Paisagem Ferroviária: MeMória e IDENTIDADE DO BAIRRO ESTAÇÃO SÃO BERNARDO (ATUAL SANTO ANDRÉ, SP)
}

Tese apresentada ao Curso de Pós-Graduação da Faculdade de Arquitetura e Urbanismo da USP, na área de concentração de Estruturas Ambientais Urbanas, em nível de Doutorado.

Silvia Helena F. Passarelli

Prof. Orientador Dr Carlos Eduardo Zahn 
Autorizo a reprodução e divulgação total ou parcial deste trabalho, por qualquer meio convencional ou eletrônico, para fins de estudo e pesquisa, desde que citada a fonte.

Silvia Helena F. Passarelli - e-mail: $\underline{\text { silviahp@ directnet.com.br }}$

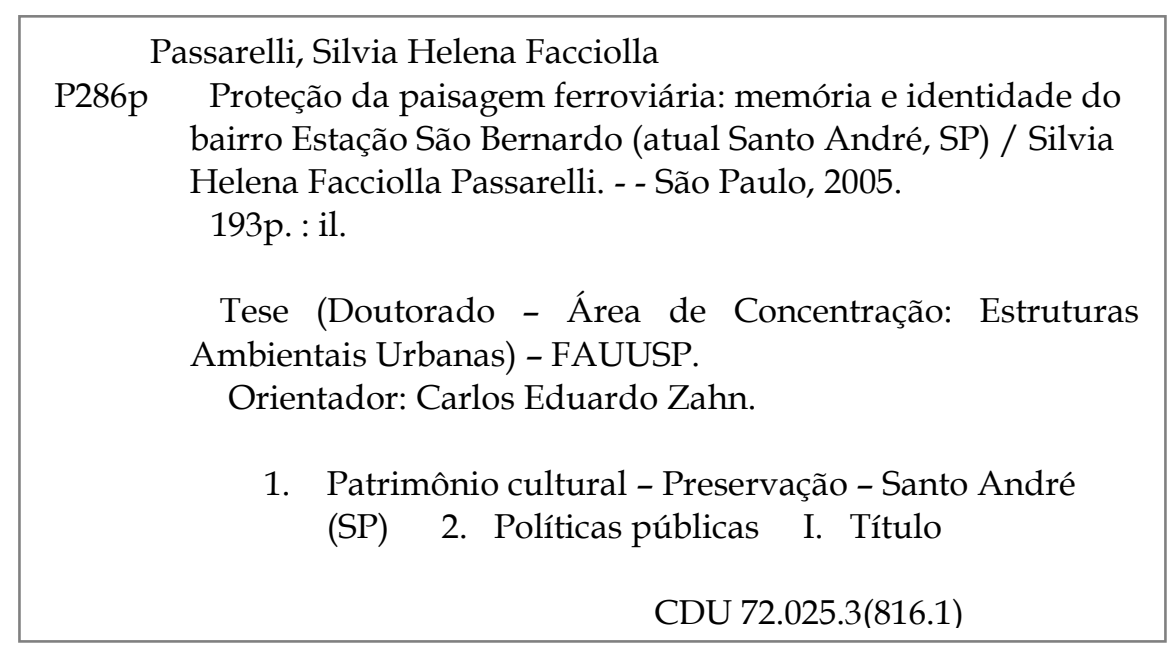




\section{ERRATA}

PÁGINA 5 - LINHA 11

Onde se lê:

É a paisagem, presente ao redor das estações ferroviárias /.../ Leia-se:

É a paisagem presente ao redor das estações ferroviárias /.../

PÁGINA 5 - LINHA 32

Onde se lê:

/.../ e proposta de intervenção, preservando alguns antigos. Leia-se:

/.../ e proposta de intervenção, preservando antigos galpões.

PÁGINA 6 - LINHA 2

Onde se lê:

/.../ projetos e estudos urbanos desenvolvidos nos órgãos /.../ Leia-se:

/.../ projetos e estudos urbanos desenvolvidos pelos órgãos /.../

PÁGINA 22 - LINHA 13

Onde se lê:

/.../ entre eles Bom Retiro, Barra Funda, Cine-Theatro e Pari, /.../ Leia-se:

/.../ entre eles Bom Retiro, Barra Funda, Moóca e Pari, /.../

PÁGINA 37 - LINHA 26

Onde se lê:

/.../ entre as estações de Santo André e São Caetano, iníciado na última /.../ Leia-se:

/.../ entre as estações de Santo André e São Caetano, iniciada na última /.../

PÁGINA 39 - LINHA 26

Onde se lê:

/.../ (denominada na planta como rua Major Flaquer), Agenor de Camargo, /.../ Leia-se:

/.../ (denominada na planta como rua Major Flaquer), Coronel Agenor de Camargo, /.../ 


\section{AgRAdeCIMENTOS}

Todo o trabalho de pesquisa acadêmica, embora desenvolvido de forma individual e solitária, conta com o apoio e estímulo de muitas pessoas, profissionais que atuam na mesma área e amigos, novos e antigos, que nos apresentam informações preciosas e nos lançam provocações e questionamentos que auxiliam o desenvolvimento das investigações necessárias para o desenvolvimento de uma tese.

Esta tese foi fruto de uma longa travessia, prática e teórica, que remonta o ano de 1985, quando iniciei minha vida profissional na Prefeitura de Santo André e minha vida afetiva com a cidade e seus moradores e o desejo de investigar mais profundamente questões de desenvolvimento urbano e proteção do patrimônio cultural, a quem não poderia deixar de agradecer.

Aos amigos de todas as horas, Iná Rosa, com quem dividi muitas dúvidas e angústias; William Gripp que mesmo de muito longe incentivou todo o processo deste trabalho; Ronaldo Tadeu Paula e Silvana Gimenes, por todas as sugestões bibliográficas; Cheila Bailão e Fernando Portela que sempre tiveram tempo para trocar idéias sobre o tema; Altair Moreira e Luiz Gustavo Della Noce pelas inúmeras conversas entre xícaras de café.

A Artur Cole, Gilson Lameira e Mirandulina Azevedo que respeitaram as minhas ausências para a finalização deste e, mais uma vez, ao Gilson, pela oportunidade que me deu, durante todo o ano de 2002, de percorrer as ruas paralelas à Estrada de Ferro Santos Jundiaí, no caminho diário entre Santo André e o Pari.

Ao corpo diretivo e técnico da Secretaria de Desenvolvimento Urbano e Habitação, Rosana Denaldi, Joel Felipe, Reinaldo Bascchera, Cibele Broiato, Regina Kubota e Valeria Delaguardia, que facilitou o acesso aos mapas à base digital do município, fundamental para a pesquisa. E aos responsáveis pelos acervos dos setores de Cadastro Fiscal e Imobiliário, da Secretaria de Finanças e de Periódicos da Biblioteca Nair Lacerda, da Prefeitura de Santo André, que forneceram condições favoráveis para a pesquisa.

Aos amigos e colegas de trabalho na área de memória, insistentes na guarda e, principalmente, na divulgação de informações sobre a história da cidade no cotidiano das atividades do Museu de Santo André, Wilson Stanziani, Suzana Kleeb, Margareth, Márcia, Diva e Silvia, agradeço pela acolhida, pelo carinho e pela troca de informações que muito auxiliou nesta reflexão.

Aos incansáveis pesquisadores e memorialistas da Região $\mathrm{ABC}$, importantes referências para a pesquisa e amigos de todas as horas: Philadelpho Brás, José Duda, Antonio Andrade, Doraci Sponcchiato, Jorge Magyar, Renato Dotta. Ao 
pessoal da Livraria e Editora Alpharrabio, em especial à Dalila e Maninha Teles Veras, pela acolhida e pelo cafezinho a qualquer hora e por possibilitarem o acesso ao "núcleo $A B C^{\prime}$ 's", um acervo de livros, revistas e artigos de jornais sobre o $\mathrm{ABC}$ e um constante e rico debate sobre a cultura regional, e à Nora Corrêa, por sua colaboração na revisão final do texto.

Aos professores do Curso de Pós-Graduação da Faculdade de Arquitetura e Urbanismo da Universidade de São Paulo, Murillo Marx, Rebeca Scherer e José Luiz Ronca, que em momentos diferentes durante o desenvolvimento do Curso para o Mestrado e para o Doutorado, estimularam a investigação do tema, auxiliando a aprofundar o estudo das relações entre a cidade e a ferrovia.

Aos professores Cibele Taralli e Marcelo Romero que, durante o Exame de Qualificação, destacaram pontos importantes para o desenvolvimento do tema com valiosas críticas para correções para a abordagem da tese.

E, ao Professor Carlos Eduardo Zahn, que, na qualidade de orientador, foi rigoroso em resguardar o caráter científico da pesquisa e paciente nos momentos de crise - e foram muitos - sempre apresentando um olhar crítico e novos questionamentos que me auxiliaram a me manter nos trilhos. À Maria de Fátima Schifino que, independente do horário, sempre trouxe uma voz amiga e tranqüilizadora pelo telefone.

Finalmente, agradeço à minha família: aos meus pais, responsáveis por permitir que a cidade fosse percorrida e percebida desde a infância. Aos meus irmãos José Carlos, pelo estímulo à reflexão, Luiz e Antonio pelos questionamentos e provocações, e Carlos, por compartilhar inúmeros momentos de desvendar o espaço urbano nas salas de cinema, de teatro e de exposições - agradeço pelo companheirismo nas aventuras de conhecer o espaço urbano; à Ângela e Mônica, por embarcarem nestas experiências de desvendar a história da cidade; e à nova geração, Fabio, Marina, Pedro e Giulia, que, pela curiosidade natural da infância e adolescência, têm contribuído na realização de novas descobertas. 


\section{SUMÁRIO}

$\begin{array}{ll}\text { Introdução } & 01\end{array}$

A paisagem ferroviária 02

Procedimentos metodológicos 08

\section{Capítulo 1}

$\begin{array}{ll}\text { A primeira ferrovia paulista } & 12\end{array}$

A Estrada de Ferro de São Paulo 14

A primeira fase de operação da via férrea 20

A duplicação da via férrea $\quad 23$

\section{Capítulo 2}

A formação do "povoado-estação" 29

O legado da ferrovia na Região ABC 30

O bairro da Estação São Bernardo 34

O parcelamento do solo para fins urbanos 37

A ocupação do solo 44

\section{Capítulo 3}

Visões do Patrimônio Cultural

Patrimônio cultural e identidade 52

Visões do patrimônio na Região do ABC 57

A ação regional 64

\section{Capítulo 4}

Gestão urbana e do patrimônio cultural em Santo André $\quad 68$

A origem do controle do solo urbano $\quad 69$

A instituição do planejamento urbano 73

$\begin{array}{ll}\text { A instituição do patrimônio cultural } & 78\end{array}$ 


\section{Capítulo 5}

Permanências do "povoado-estação" em Santo André 93

Elementos urbanos da paisagem ferroviária $\quad 94$

A ocupação do solo ao longo das estradas e caminhos 101

Caminho do Pilar 101

Caminho para São Caetano 103

Estrada do Oratório 104

Caminho para estrada João Ducim 106

Estrada do Guarará $\quad 107$

Estrada do Sertão dos Beber 109

Avenida Queirós dos Santos $\quad 110$

A ocupação do bairro da Estação 112

Os arredores da estação ferroviária $\quad 112$

Villa Ypiranguinha 114

Terrenos da Companhia Industrial de São Bernardo 119

Vila Operária da Fábrica "Ypiranguinha" 120

Villa Flaquer 122

Villa Alzira 126

Permanências da paisagem ferroviária fora do bairro da Estação 128

Considerações finais $\quad 132$

$\begin{array}{ll}\text { Paisagem ferroviária e identidade regional } & 133\end{array}$

Recomendações para política de preservação do patrimônio 140

$\begin{array}{ll}\text { Anexo } & 148\end{array}$

Listagem preliminar de bens que preservam, total ou parcialmente, elementos da paisagem ferroviária em Santo André

\section{Bibliografia}

Referências bibliográficas $\quad 174$

Referências cartográficas $\quad 180$

Bibliografia consultada $\quad 181$

$\begin{array}{ll}\text { Sobre o espaço urbano } & 181\end{array}$

Sobre a formação urbana da Região ABC 182 
Sobre caminhos de rodagem e de ferro 184

$\begin{array}{ll}\text { Cartografia consultada } & 185\end{array}$

$\begin{array}{ll}\text { Coleções e Periódicos } & 186\end{array}$

\section{Apêndice}

Inventários de bens culturais de Santo André

Inventários Históricos (1987) 188

Inventário de bens de interesse urbanístico (1998) 190

ÍNDICE DOS MAPAS

Mapa 01 Santo André e a Região ABC.

Mapa 02 Planta Geral da São Paulo Railway entre Santos e São Paulo e das linhas estudadas na Serra do Mar.

Mapa 03 Mapa do Transporte Metropolitano de São Paulo.

Mapa 04 Levantamento topográfico do Estado de São Paulo (parcial, com foco nos atuais centros urbanos de Santo André, São Bernardo do Campo, São Caetano do Sul e São Paulo).

Mapa 05 Levantamento topográfico do Estado de São Paulo (parcial, focando os atuais centros urbanos de Santo André, São Bernardo do Campo, São Caetano do Sul)

Mapa 06 Caminhos e parcelamentos do bairro da Estação São Bernardo

Mapa 07 Proteção da paisagem ferroviária - Caminhos

Mapa 08 Proteção da paisagem ferroviária - Parcelamentos 
CMSB - Câmara Municipal de São Bernardo.

COMDEPHAAPASA - Conselho Municipal de Defesa do Patrimônio Histórico, Artístico, Arquitetônico-Urbanístico e Paisagístico de Santo André.

CONDEPHAAT - Conselho de Defesa do Patrimônio Histórico, Arqueológico, Artístico e Turístico do Estado de São Paulo.

CPTM - Companhia Paulista de Trens Metropolitanos.

DAESP - Departamento do Arquivo do Estado de São Paulo.

IPHAN - Instituto do Patrimônio Histórico, Artístico e Nacional.

MuSA - Museu de Santo André.

PMSA - Prefeitura Municipal de Santo André.

RFFSA - Rede Ferroviária Federal Sociedade Anônima. 


\section{RESUMO}

Desde os anos 1980, tem sido freqüente a adoção de práticas de valorização e recuperação do patrimônio cultural como meio de reabilitação de espaços urbanos degradados, visando a revitalização dos centros urbanos, através da reinserção de edifícios e conjuntos de valor histórico no cotidiano da cidade por meio de novos usos, adotando um novo paradigma de desenvolvimento que se contrapõe às práticas de renovação urbana.

Também no município de Santo André a gestão pública tem buscado alternativas de valorização da memória e do patrimônio cultural desde os primeiros anos da década de 1990, parte de um processo que dez anos atrás havia se iniciado por meio de debates públicos sobre a salvaguarda do patrimônio, amplamente registrados pela imprensa escrita local.

No entanto, embora as diretrizes de desenvolvimento econômico e social da administração local enfatizem a importância do resgate da memória como afirmação da identidade local, os elementos urbanos remanescentes da paisagem do antigo Bairro da Estação de São Bernardo não têm recebido atenção adequada das políticas de desenvolvimento urbano pelo desconhecimento do valor de inúmeros edifícios e logradouros espalhados na cidade ou mesmo por falta de instrumentos legais para a preservação.

Esta tese propõe como hipótese de trabalho afirmar que há permanência de remanescentes da memória fundadora da paisagem do "povoado-estação" que se formou ao redor da estação Santo André que merecem ser identificados, valorizados e protegidos, conforme estabelecem as cartas e resoluções de congressos e seminários internacionais de proteção do patrimônio cultural.

A partir da identificação dos elementos urbanos que se identificam com remanescentes da paisagem ferroviária, este trabalho propõe a realização de uma reflexão sobre as práticas de valorização e preservação do patrimônio ambiental urbano experimentado no município de Santo André e propõe alternativas para a salvaguarda do patrimônio cultural local.

\section{PALAVRAS-ChAVE}

Patrimônio cultural, salvaguarda, identidade urbana, política pública, Santo André e Região $\mathrm{ABC}$. 


\section{ABSTRACT}

Since the decade of 1980, it has been recurrent the adoption of practices of valuation and recuperation of cultural patrimony as a means of urban spaces renewal aiming at urban centers revitalization, by means of reinsertion of buildings and historical clusters at city's daily life with new kinds of using, which adopts a development paradigm that is contradictory to urban renewal practices.

Also in the municipality of Santo André, the public power has searched for alternatives of memory and cultural patrimony valuation early in the decade of 1990, as part of a process that had been started off ten years ago with public debates about the patrimony safeguard, widely registered by the local press.

However, although the social and economical development guidelines of the local administration highlight the importance of the rescue of memory as a local identity's affirmation, the reminiscent urban elements from São Bernardo's former 'Bairro da Estação' have not been receiving adequate attention by urban development policies for the unfamiliarity with the value of innumerable buildings and public lots spread in the city, or even for the lack of preservation legal tools.

This thesis proposes, as work hypothesis, to state that there is permanence of reminiscents of the "station-town" establishing memory, which has been formed around the train station of Santo Andre and are worthy of identification, valuation and protection, as it has been stated by documents and resolutions from international congresses and seminars on cultural patrimony protection.

From the identification of urban elements that are identified with the railway scape, this work proposes a reflection on the practices of valuation and preservation of the urban environment patrimony experienced in the municipality of Santo André, and proposes alternatives to the safeguard of the local cultural patrimony. 